\title{
Comparison of disinfection effect between benzalkonium chloride and povidone iodine in nasotracheal intubation: a randomized trial
}

Aiji Sato-Boku ${ }^{1 *}$ (D) Keiji Nagano ${ }^{2}$, Yoshiaki Hasegawa ${ }^{3}$, Yuji Kamimura ${ }^{4}$, Yoshiki Sento ${ }^{4}$, MinHye So ${ }^{4}$, Eisuke Kako ${ }^{4}$, Masahiro Okuda ${ }^{1}$, Naoko Tachi ${ }^{1}$, Hidekazu Ito ${ }^{5}$, Yushi Adachi ${ }^{6}$ and Kazuya Sobue ${ }^{4}$

\begin{abstract}
Background: Nasotracheal intubation can potentially result in microbial contamination from the upper respiratory tract to the lower respiratory tracts. However, an ideal nasotracheal disinfection method is yet to be determined. Therefore, we compared the disinfection effects between benzalkonium chloride and povidone iodine in nasotracheal intubation.

Methods: Overall, this study enrolled 53 patients aged 20-70 years who were classified into classes 1 and 2 as per American Society of Anesthesiologists-physical status and were scheduled to undergo general anesthesia with NTI. Patients who did not give consent $(n=2)$ and who has an allergy for BZK or PVI were excluded from the study. The patients were randomly divided into two groups on the basis of the disinfection method: BZK ( $n=26$, one patient was discontinued intervention) and PVI $(n=25) .50$ patients were assessed finally.

The subjects' nasal cavities were swabbed both before (A) and after disinfection (B), and the internal surface of the endotracheal tube was swabbed after extubation (C). The swabs were cultured on Brain heart infusion agar and Mannitol salt agar. The number of bacteria per swab was determined and the rates of change in bacterial count (B/A, C/B) were calculated. The growth inhibitory activity of the disinfectants on Staphylococcus aureus were also investigated in vitro.

Results: Although the initial disinfection effects (B/A) were inferior for benzalkonium chloride compared with those for povidone iodine, the effects were sustained for benzalkonium chloride (C/B). In the in vitro growth inhibitory assay against $S$. aureus, benzalkonium chloride showed higher inhibitory activity than povidone iodine.

Conclusion: Although both disinfectants were inactivated or diffused/diluted over time, benzalkonium chloride maintained the threshold concentration and displayed antimicrobial effects longer than povidone iodine; therefore, benzalkonium chloride appeared to show a better sustained effect. Benzalkonium chloride can be used for creating a hygienic nasotracheal intubation environment with sustained sterilizing effects.
\end{abstract}

Trial registration: UMIN-CTR (Registration No. UMIN000029645). Registered 21 Oct 2017.

Keywords: Nasotracheal intubation, Benzalkonium chloride, Povidone iodine, Bacteremia

\footnotetext{
* Correspondence: bokuaiji@dpc.agu.ac.jp

${ }^{1}$ Department of Anesthesiology, Aichi Gakuin University School of Dentistry,

2-11 Suemori-dori, Chikusa-ku, Nagoya 464-8651, Japan

Full list of author information is available at the end of the article
}

(c) The Author(s). 2019 Open Access This article is distributed under the terms of the Creative Commons Attribution 4.0 International License (http://creativecommons.org/licenses/by/4.0/), which permits unrestricted use, distribution, and reproduction in any medium, provided you give appropriate credit to the original author(s) and the source, provide a link to the Creative Commons license, and indicate if changes were made. The Creative Commons Public Domain Dedication waiver (http://creativecommons.org/publicdomain/zero/1.0/) applies to the data made available in this article, unless otherwise stated. 


\section{Background}

Nasotracheal intubation (hereafter referred to as "NTI") is frequently necessary during dental, maxillofacial, and oropharyngeal surgeries. This method is also useful while operating on patients with respiratory insufficiency, patients who require long-term maintenance of the airway in the intensive care unit and patients in whom orotracheal intubation is difficult because of trismus. However, some complications associated with NTI include epistaxis [1, 2], bacteremia [3], retropharyngeal perforation [4], and partial or complete obstruction of the tube $[5,6]$. NTI complications are some of the many causes of anesthesia-related mortality [7].

Although several effective preventive measures against epistaxis and retropharyngeal perforation have been reported [8-10], an effective disinfection method during NTI is yet to be determined. In fact, dental procedures under general anesthesia with NTI demonstrate a higher incidence of bacteremia compared with those conducted under local anesthesia [3]; moreover, patients with prosthetic heart valves, immunodeficient patients, diabetic patients, and patients taking steroids are at an increased risk of bacteremia, and such patients require antibiotic prophylaxis [11]. Reports describing the presence of NTI-related bacteremia also exist $[11,12]$. Bacteremia is likely caused by transferring intranasal bacteria into the respiratory tract. Therefore, the disinfection of the nasal mucosa before nasal intubation is crucial for avoiding the contamination of respiratory organs by nasal microorganisms.

In Japan, benzalkonium chloride (hereafter referred to as "BZK") and povidone iodine (hereafter referred to as "PVI") are generally used as NTI disinfectants. A comprehensive literature search was performed using PubMed, the Cochrane Central Register of Controlled Trials and EMBASE. However, to the best of our knowledge, the authors were unable to identify any previous reports comparing the outcomes of disinfection effects between these two disinfectants. Therefore, we investigated the disinfection effects of BZK and PVI when used for disinfection in NTI.

\section{Methods}

\section{Ethics approval and consent to participate}

This study was approved by the Ethics Committee at the School of Dentistry, Aichi Gakuin University (Approval No. 495) and was registered prospectively in the UMINCTR as a clinical trial on 21 Oct 2017. (Registration No. UMIN000029645). Our study adhered to CONSORT guidelines. The first patient was recruited and registered on 23 Oct 2017 (https://upload.umin.ac.jp/cgi-bin/ctr/ctr view_reg.cgi?recptno=R000033873). We obtained written informed consent from all patients after providing them with adequate explanation regarding the research aims.

\section{Subjects}

Overall, this study enrolled 53 patients aged $20-70$ years who were classified into classes 1 and 2 as per American Society of Anesthesiologists-physical status (hereafter referred to as "ASA-PS") and were scheduled to undergo general anesthesia with NTI. Patients who did not give consent $(n=2)$ and who has an allergy for BZK or PVI were excluded from the study. The patients were randomly divided into two groups on the basis of the disinfection method: BZK $(n=26$, one patient was discontinued intervention) and PVI $(n=25) .50$ patients were assessed finally (Fig. 1).

\section{Anesthesia, sample collection, and microbial count}

The same method of anesthesia was employed for all patients. No premedication was administered. After a patient walked independently to the operating theater, the standard vital monitors (electrocardiogram, blood pressure and oxygen saturation) were monitored. Anesthesia was induced using propofol $(1-2 \mathrm{mg} / \mathrm{kg})$, remifentanil $(0.2 \mu \mathrm{g} / \mathrm{kg} / \mathrm{min}$.), and fentanyl $(100 \mu \mathrm{g})$, with rocuronium $(0.6 \mathrm{mg} / \mathrm{kg})$ used as a neuromuscular blocking agent. Until the effects of the neuromuscular blocking agent became apparent, mask ventilation was implemented for all patients using 100\% oxygen. While mask ventilation was being performed, the subjects' inferior nasal passage was swabbed with a sterile cotton swab before disinfection (A). The subjects' nasal cavities and inferior nasal passages were adequately disinfected twice each using a sterile cotton swab with BZK (ZALKONIN ${ }^{\circ}$ SOLUTION 0.025, Kenei Phamaceutical Co., Ltd., Osaka) or PVI (POVIDONE-IDOINE SOLUTION 10\%「MEIJI」Nitto Medic Co., Ltd., Toyama). BZK and PVI were applied at normal clinical concentrations of 0.025 and 5\%, respectively. Next, the patients' inferior nasal passages were swabbed again with sterile cotton swabs after disinfection (B). Then, tramazoline nasal drops were administered to the nasal cavity and NTI was conducted after the muscle relaxant was observed to take effect. In all cases, we maintained general anesthesia using Total Intra Venous Anesthesia. After the surgery, the internal surface of the endotracheal tube (inner surface $1 \mathrm{~cm}$ from the tip of the tube) was swabbed immediately after extubation (C). We focused on how much bacteria that invaded from the upper airway to the lower airway during intubation was suppressed by long-term disinfection effect. If we swabbed the outer surface of the endotracheal tube, we could not avoid contamination by nasal bacteria during extubation. Therefore, we swabbed the the internal surface of the endotracheal tube.

After collecting the specimens, only the swab head was cut off. The samples from (A) and (C) were placed in $10 \mathrm{ml}$ of sterile physiological saline and the samples from (B) were placed in $40 \mathrm{ml}$ of sterile physiological 


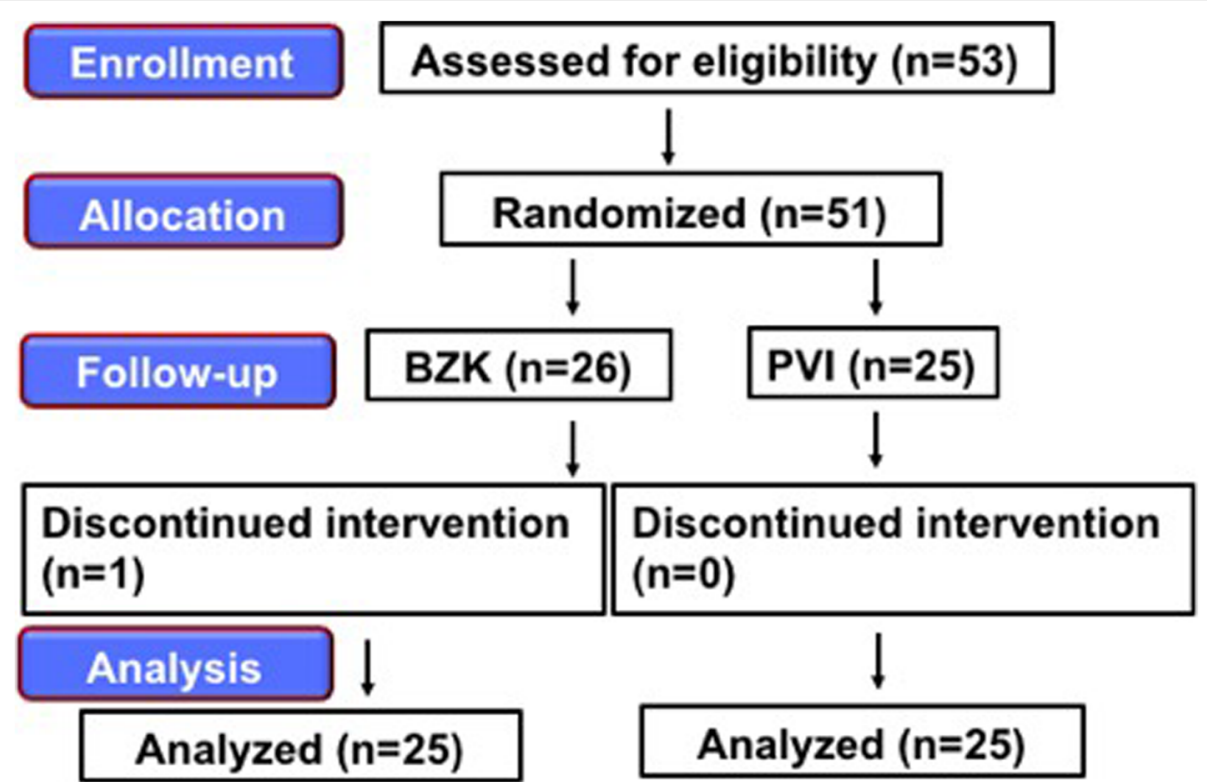

Fig. 1 Consolidated Standards of Reporting Trials (CONSORT) recommended description of patient recruitment

saline to dilute the disinfectants (BZK or PVI) that were absorbed by the swab. The samples were refrigerated and submitted for examination within six hours as described in the following sections.

Viable microbes in the swab samples were measured using a culture method. The samples were vigorously vortexed at maximum speed for $30 \mathrm{~s}$ to extract the microbes from the swab head in saline. After the swab heads were removed, the samples were centrifuged at $4000 \times g$ for $15 \mathrm{~min}$ at $4{ }^{\circ} \mathrm{C}$ to concentrate the extracted microbes, and then the precipitates were suspended in 1 $\mathrm{ml}$ of saline. The precipitates were serially diluted, and $50 \mu \mathrm{l}$ of the dilutions was spread on agar plate medium. Brain heart infusion agar (hereafter referred to as "BHI", Becton, Dickinson and Company, Franklin Lakes, NJ, USA) was used for assessing the total number of microbes. Mannitol Salt Agar (hereafter referred to as "MTS", Nissui Pharmaceutical Co., Ltd., Tokyo, Japan) was used for detecting Staphylococcus. After culturing at $37^{\circ} \mathrm{C}$ for $24 \mathrm{~h}$ under aerobic conditions, the colonies were counted and were expressed as colony-forming units (hereafter referred to as "CFU").

\section{Assay for minimum inhibitory concentration (hereafter referred to as "MIC")}

The MICs of the gram-positive bacterium $S$. aureus strain FDA 209P JC-1 against BZK and PVI were examined using both BHI agar and broth media. Approximately $10^{6} \mathrm{CFU}$ of bacterial cells were inoculated in the media and cultivated at $37^{\circ} \mathrm{C}$ for $24 \mathrm{~h}$ under aerobic conditions. The MICs were visually determined.
The evaluation of parameters

The preoperative patient attributes of sex, age, anesthesia time, and patient distribution after extubation were evaluated. The numbers of bacteria (in CFU) in the samples from (A), (B), and (C) per cotton swab were assessed, and the rates of change in bacterial count $(\mathrm{B} / \mathrm{A}$, $\mathrm{C} / \mathrm{B}$ ) were calculated. The MICs were also visually determined.

\section{Statistical analysis}

We calculated the required minimum number of samples ( $n=46$ cases; BZK group, 23 cases; PVI group, 23 cases; effect size, 0.47 ; $\alpha$-error, 0.05; power, 0.95). The effect size was calculated on the basis of the statistical results of a pilot study in which the patient distribution for the change in the number of bacteria after disinfection was used as a standard [BZK group, 10 cases; PVI group, 10 cases]. As application of statistical tests in the absence of reliable sample size calculation decrease its weightage, we calculated our final sample size as follows. The dropout rate in a preliminary study was 0.05 . If an $\mathrm{R}$ dropout rate is expected, a simple but adequate adjustment is provided by $\mathrm{N}_{d}=\mathrm{N} /(1-\mathrm{R})^{2}$ where $\mathrm{N}$ is sample size calculated assuming no dropout and $\mathrm{N}_{\mathrm{d}}$ that required with dropouts [13]. Therefor our adjustment was 50.9 and 50 patients were assessed finally. Student's $t$ test was used for assessing the effects of age and anesthesia time. Chi-square independence test $m \times n$ contingency table was used for assessing sex and patient distributions. Based on the results of QQ plot from the sample (A), (B) and (C), Mann-Whitney U test was used for the number of bacteria found in the samples from 
(A), (B), (C) and the rates of change in bacterial count (B/A, C/B). The level of statistical significance was set at $p<0.05$.

\section{Results}

From October 2017 to December 2017, 53 patients were selected as subjects for this study. Figure 1 shows the consort flow diagram. Fifty-one subjects were randomly assigned into two groups on the basis of the disinfection method used: BZK and PVI. One subject dropped out during the trial.

Table 1 shows patient sex, age, and anesthesia time. No statistical differences in any parameters were observed between the two groups.

For examining the total number of bacteria, we used BHI for the general bacterial culture (Table 2). The number of nasal bacteria before disinfection (A) was equivalent in the BZK and PVI groups $(30,000$ and 50, $000 \mathrm{CFU} / \mathrm{swab}$, respectively) and no statistically significant differences were noted. However, individual patient differences were large and ranged from 1900 to 400,000 $\mathrm{CFU} / \mathrm{swab}$. After disinfection (B), the bacterial numbers of $1300 \mathrm{CFU} / \mathrm{swab}$ for BZK and $20 \mathrm{CFU} /$ swab for PVI were reported, which correspond to a difference of 65 times $(p=0.00005)$. The rate of change $(\mathrm{B} / \mathrm{A})$ was also significantly lower for PVI than for BZK. Conversely, postoperatively $(C)$, both groups reported a median of 1900 CFU/swab. Compared with the samples from (B), there was barely any change in the number of bacteria in the samples from $(\mathrm{C})$ after BZK treatment, whereas after PVI treatment, an approximately 100 -fold proliferation was observed: The rate change $(\mathrm{C} / \mathrm{B})$ for $\mathrm{BZK}$ and PVI was100 and 9867, respectively $(p=0.002)$.

Table 3 shows the number of bacteria in the samples from (A), (B), and (C) in MTS and the rates of change for $B / A$ and $C / B$. The number of nasal bacteria before disinfection (A) was equivalent in patients in the BZK and PVI groups $(10,000$ and $7000 \mathrm{CFU} / \mathrm{swab}$, respectively) and there was no statistically significant difference noted. However, the individual differences were large and ranged from 900 to 30,000 CFU/swab. After disinfection (B), bacterial numbers of $200 \mathrm{CFU} / \mathrm{swab}$ for BZK and $20 \mathrm{CFU} /$ swab for PVI were reported, and a difference of 100 times was confirmed $(p=0.002)$. The rate of change (B/A) was significantly lower after PVI disinfection than after BZK disinfection. Conversely, postoperatively $(\mathrm{C})$, both groups reported an identical median of $20 \mathrm{CFU} / \mathrm{swab}$. Compared with the samples from (B), the number of bacteria found in the samples from (C) decreased after BZK disinfection, whereas an increase in the number of bacteria in the samples from (C) after PVI disinfection was observed, when compared between their quartiles.

Tables 4 and 5 show patient distribution regarding the change in the number of bacteria after disinfection. Compared to BZK, more patients with PVI disinfection displayed increased numbers of bacteria after extubation in both media.

The MICs of BZK and PVI against S. aureus were examined (Table 6). BZK inhibited S. aureus when diluted up to $2^{9}$ times, but PVI only inhibited $S$. aureus when diluted up to $2^{6}$ times.

\section{Discussion}

Previous reports have discussed the development of bacteremia due to bacterial flora associated with the upper respiratory tract (hereafter referred to as "URT") during treatment [3, 14-17]. Notably, during tracheal intubation, there is a high possibility for the bacterial flora in the nasopharyngeal region to gain access to the trachea. During intubation, host defense mechanisms that remove bacterial pathogens from URT, which would subsequently enter the lower respiratory tract, are impaired. In addition, the frequency of bacteremia after nasotracheal intubation is not related to the use of drugs for blood vessel contraction or the degree of trauma during the procedure [11].

Based on the hypothesis that Staphylococcus sp. is an important etiological agent associated with NTI, we used MTS, a selective medium for Staphylococcus sp., in this study. Although yellow colonies were frequently isolated, some white colonies were also isolated. On Gram staining of selective specimens, because the yellow and white colonies obtained appeared to be gram-positive cocci

Table 1 Characteristics of patients in this study

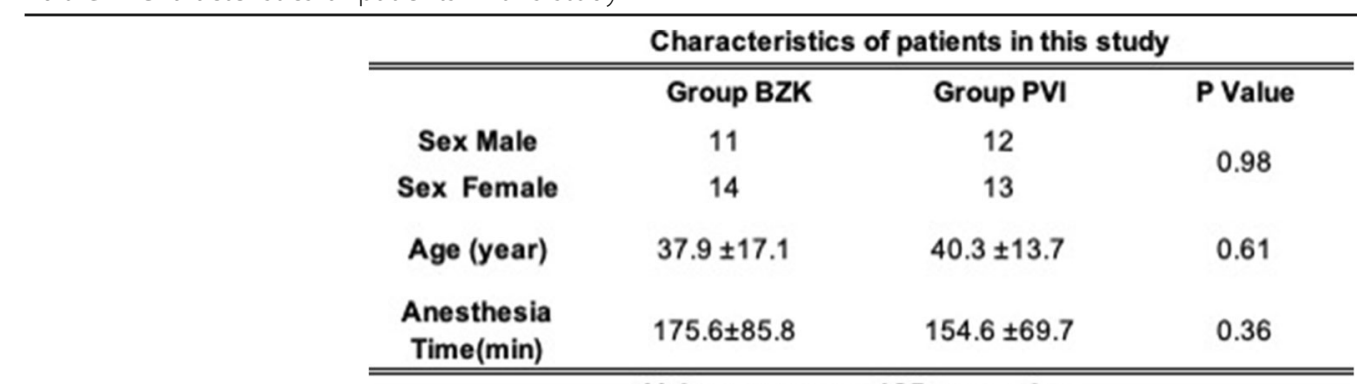

Values are mean 1SD or number 
Table 2 The effect of BZK or PVI for General bacteria

\begin{tabular}{cccc} 
& \multicolumn{3}{c}{ The effect of BZK or PVI for General bacteria } \\
\hline \hline & Group BZK & Group PVI & P Value \\
A (CFU) & 30000 & 50000 & 0.23 \\
& $(1900-100000)$ & $(6000-400000)$ & \\
B (CFU) & 1300 & 20 & 0.00005 \\
C (CFU) & $(100-9400)$ & $(20-20)$ & \\
& 1900 & 1900 & 0.93 \\
B/A (\%) & $(320-7700)$ & $(40-2200)$ & \\
& $(2.7-18.25)$ & $(0.01-0.31)$ & 0.000001 \\
C/B (\%) & 100 & 9867 & 0.002 \\
\hline \hline
\end{tabular}

Values are median (quartile)

forming grape-like clusters, they were considered to be S. aureus and S. epidermidis, respectively.

In this study, the main bacterial isolates obtained from the nasal cavity were $S$. aureus and $S$. epidermidis. Because Staphylococcus sp. causes endocarditis [18], disinfection of the nasal cavity prior to nasotracheal intubation is extremely important to reduce the bacterial load.

Following antisepsis of the nasal cavity, the swab sampling the mucous membrane was placed in $40 \mathrm{ml}$ of saline. The swab head can absorb approximately 0.135 $\mathrm{ml}$ of fluid. When the same volume of antiseptic (BZK or PVI) is absorbed by a swab during mucosal membrane swabbing and placed in $40 \mathrm{ml}$ of saline, the sample is diluted 296-fold. Although S. aureus MICs of BZK and PVI were achieved after 512-fold and 64-fold dilutions, respectively, no antibacterial effect was expected theoretically because PVI was diluted below the MIC. However, the initial disinfection efficacy of PVI was higher than that of BZK, suggesting that dilution does not affect disinfection efficacy.
Because PVI has wide-spectrum disinfection properties with low levels of irritation, it is used for local applications during surgery and for infections of the oral and vaginal mucosa. Although PVI displays a rapid disinfection efficacy at low concentrations (approximately $0.1 \%$ ) under experimental conditions, it can lose significant disinfection efficacy in the presence of organic matter; therefore, a $5-10 \%$ concentration is used in clinical settings. It is reported that 10 min was required for appearance of the bactericidal effect of PVI in clinical application, which organic matter was present [19]. However, we intubated immediately (1 to $2 \mathrm{~min}$ ) after the disinfections in this study, but B/A values indicate that PVI was superior to BZK for initial disinfection. Our results suggest that reconsideration is necessary for PVI usage including an incubation time after application. Additionally, it does not seem to wait for $10 \mathrm{~min}$ after PVI treatment in general application. As mentioned above, PVI normally exhibits sufficient disinfection effect by waiting for $10 \mathrm{~min}$ after disinfection.

Table 3 The effect of BZK or PVI for Staphylococci

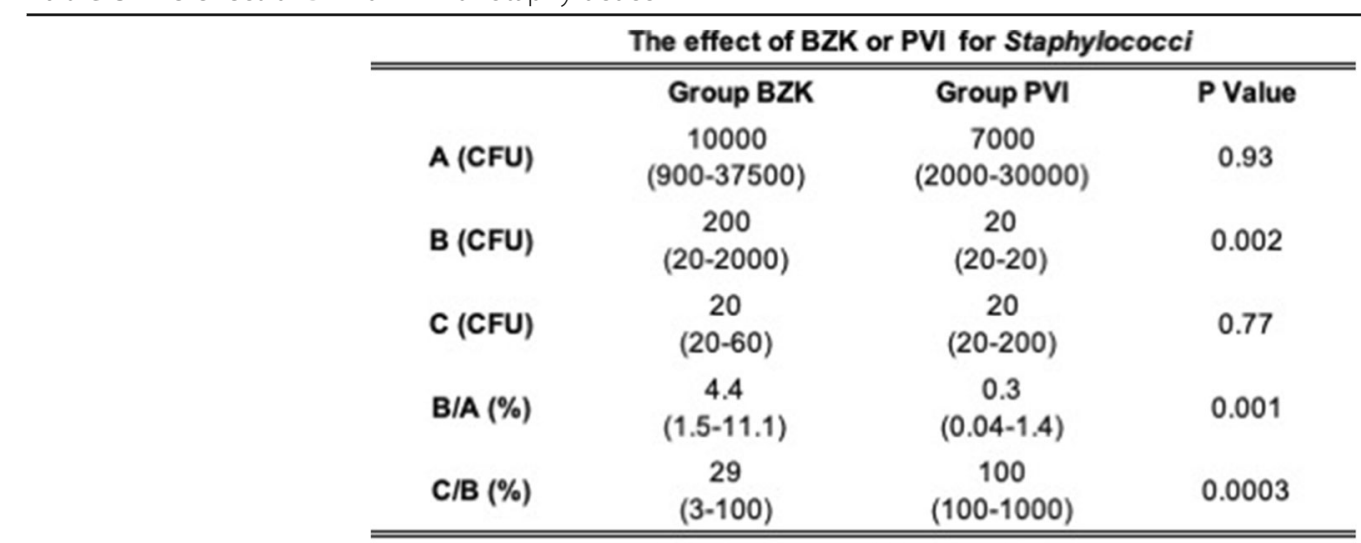

Values are median (quartile) 
Table 4 Patient distribution regarding the change in the number of General bacteria after disinfection

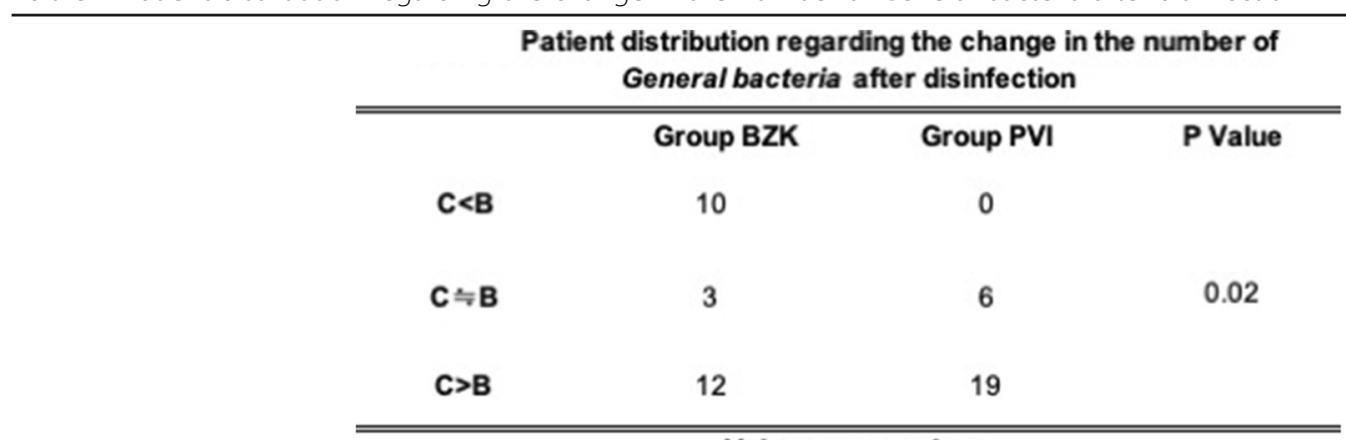

Values are number

In this study, although we intubated 1-2 min after disinfection with PVI, the initial disinfection effect was sufficient. However, if intubation was performed $10 \mathrm{~min}$ after disinfection, it may have been possible to suppress bacterial growth in $\mathrm{C}$ by exerting the original disinfection effect.

BZK continued to demonstrate a high disinfection efficacy following extubation, whereas increased bacterial levels were found after PVI disinfection. Because the clinical samples following extubation represent specimens incide the endtracheal tube, re-contamination due to bacterial flora in the nasal cavity during extubation is considered to be extremely unlikely. Therefore, the increased bacterial levels detected after extubation indicated that the growth of bacteria originally introduced into the trachea at the time of intubation develops even in a short intubation time during surgery and the disinfection effect of PVI is not sustained.

This study clearly showed that the disinfection efficacy of BZK was sustainable. In vitro, BZK inhibited the growth of $S$. aureus even at a dilution of $2^{9}$, whereas PVI inhibited growth at a dilution of $2^{6}$. Although both disinfectants were inactivated or diffused/diluted over time,
BZK maintained the threshold concentration and displayed antimicrobial effects longer than PVI; therefore, BZK appeared to show a better sustained effect.

There are some limitations of this study. First, with respect to bacterial counts, there were major differences in callosity among patients. There are many reasons for the variation in callosity. The level of mucosal membrane dryness in the nasal cavity can affect callosity. In the future, it may be necessary to adjust for mucosal membrane dryness prior to specimen collection. Second, multiple practitioner were participated in this study. Prior to beginning the study, disinfection methods were standardized as much as possible; however, disinfection efficacy did not account for differences among individuals. Although this study demonstrated that PVI showed immediate effects, the results may have differed if one healthcare person performed all procedures.

Third, since we only disinfect the nasal cavities and inferior nasal passages, we cannot rule out that nasoand oro-pharyngeal contamination during intubation contributed to our results. We also have not performed blood tests before and after disinfection. Therefore, we

Table 5 Patien distribution regarding the change in the number of Staphylociccu after disinfection

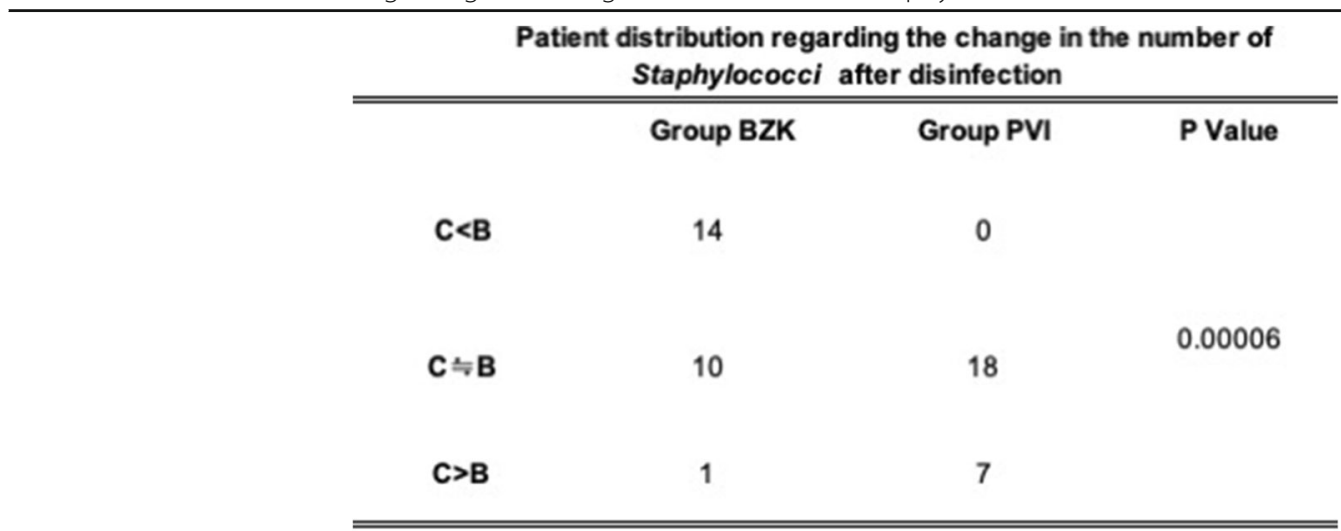


Table 6 Growth inhibition effect of Staphylococcus aureus (MICs)

Growth inhibition effect on Staphylococcus aureus (MICs)

\section{BZK PVI}

Dilution

$2^{9}$ times

$2^{6}$ times

may have had to discuss more solid evidence based on blood test for bacteremia.

Forth, since our research is a single-institutional research, longitudinal, multicentric, large population randomized controlled studies comparing the disinfection effects of variety of disinfectants over variety of microorganisms may be necessary to derive a valid conclusion.

\section{Conclusion}

We investigated the disinfection effects of benzalkonium chloride and povidone iodine when used for disinfection in nasotracheal intubation. Although both disinfectants were inactivated or diffused/diluted over time, benzalkonium chloride maintained the threshold concentration and displayed antimicrobial effects longer than povidone iodine. Benzalkonium chloride can be used for creating a hygienic nasotracheal intubation environment with sustained sterilizing effects.

\section{Abbreviation}

ASA-PS: American Society of Anesthesiologists-physical status; BHI: Brain heart infusion agar; BZK: Benzalkonium chloride; CFU: Colony-forming units; MICs: Minimum inhibitory concentration; MTS: Mannitol Salt Agar: NTI: Nasotracheal intubation; PVI: Povidone iodine; URT: Upper respiratory tract

\section{Acknowledgements}

The authors would like to thank the Department of Anesthesiology at Aichi Gakuin University Dental Hospital for their help in recruiting patients for this study.

\section{Authors' contributions}

AS and KN did the same contribution to this study. AS and KN wrote this manuscript under supervision of $\mathrm{YH}, \mathrm{MO}$ and $\mathrm{KS}$. AS, KN, YH, MO, NT, YA and YS designed the study. AS, KN, HI performed the investigation and analyzed the data. YH, YK, YS, MS, EK, MO, YA NT, HI made substantial contribution to the interruption of the data. KS was responsible for the study design, writing of the manuscript, analysis and interpretation of the data. All authors have read and approved the final manuscript.

\section{Funding}

No funding was obtained for this study.

\section{Availability of data and materials}

The datasets analysed during the current study are available from the corresponding author on reasonable request.

\section{Ethics approval and consent to participate}

This study was approved by the Ethics Committee at the Aichi Gakuin University School of Dentistry (Approval No. 495) and was registered in advance as a clinical trial in the UMIN-CTR (Registration No. UMIN000029645). Written informed consent was obtained from all the patients.

\section{Consent for publication}

Not applicable.

\section{Competing interests}

The authors declare that we have no competing interests.

\section{Author details}

'Department of Anesthesiology, Aichi Gakuin University School of Dentistry, 2-11 Suemori-dori, Chikusa-ku, Nagoya 464-8651, Japan. ${ }^{2}$ Department of Oral microbiology, School of Dentistry Health Sciences University of Hokkaido 757 Kanazawa, Ishikari-Tobetsu, Hokkaido 061-0293, Japan. ${ }^{3}$ Department of Microbiology, Aichi Gakuin University School of Dentistry, 1-100 Kusumotocho, Chikusa-ku, Nagoya 464-8650, Japan. ${ }^{4}$ Department of Anesthesiology and Intensive Care Medicine, Nagoya City University Graduate School of Medical Sciences, 1 Kawasumi, Mizuho-cho, Mizuho-ku, Nagoya 467-8601, Japan. ${ }^{5}$ Department of Anesthesiology, Aichi Developmental Disability Center Central Hospital, 713-8 Kagiya-cho, Kasugai-city, Aichi 480-0392, Japan. ${ }^{6}$ Department of Anesthesiology, Nagoya University Graduate School of Medicine, 65 Tsurumaicho, Showaku, Nagoya 466-8550, Japan.

Received: 15 April 2019 Accepted: 21 August 2019

Published online: 31 August 2019

\section{References}

1. Lee J-H, Kim C-H, Bahk J-H, Park K-S. The influence of endotracheal tube tip design on nasal trauma during nasotracheal intubation: magill-tip versus murphy-tip. Anesth Analg. 2005;101:1226-9.

2. Chen YN, Chen JY, Hsu CS, Huanq CT, So E. Recurrent epistaxis following nasotracheal intubation: a case report. Acts Anaesthesiol Sin. 1996;34:93-6.

3. Berry FA, WI B, Ball CG. A comparison of bacteremia occurring with nasotracheal and orotracheal intubation. Anesth Analg. 1973;52:873-6.

4. Chait DH, Poulton TJ. Case report: retropharyngeal perforation, acomplication of nasotracheal intubation. Nebr Med J. 1984;69:68-9.

5. Kenney JN, Laskin DM. Nasotracheal tube obstruction from a central incisor. Oral Surg Oral Med Oral Pathol. 2005;67:266-7.

6. Tintinalli JE, Claffey J. Complications of nasotracheal intubation. Ann Emerg Med. 1981;10:142

7. Harrison GG. Death attributable to anaesthesia: a 10 yr survey (1967-1976). Br J Anaesth. 1978;50:1041-6.

8. Boku A, Hanamoto $H$, Hirose $Y$, Kudo C, Morimoto $Y$, Sugimura M, Niwa H. Which nostril should be used for nasotracheal intubation: the right or left? A randomized clinical trial. J Clin Anesth. 2014;26:390-4.

9. Sanuki T, Hirokane M, Matsuda Y, Sugioka S, Kotani J. The Parker flex-tip tube for nasotracheal intubation: the influence on nasal mucosal trauma. Anaesthesia. 2010:65:8-11.

10. Morimoto $Y$, Sugimura M, Hirose $Y$, Taki K, Niwa H. Nasotracheal intubation under curve-tipped suction catheter guidance reduces epistaxis. Can J Anaesth. 2006;53:295-8.

11. Dinner M, Tjeuw M, Artusio JF. Bacteremia as a complication of nasotracheal intubation. Anesth Analg. 1987;66:460-2.

12. Berry FA, Yaubrough S, Yaubrough N. Transient bacteremia during dental manipulation in children. Pediatrics. 1973;51:476-9.

13. Lachin JM. Introduction to sample size determination and power analysis for clinical trials. Control Clin Trials. 1981;2:93-113.

14. Storm W. Transient bacteremia following endotracheal suctioning in ventilated newborns. Pediatrics. 1980;65:487-90.

15. LeFrock JL, Klainer AS, Wen-Hsien W. Transient bacteremia associated with nasotrachaal suctioning. JAMA. 1976:236:1610-1.

16. Beyt BE, King DK, Glue RH. Fatal pneumonitis and septicemia after fiberoptic bronchoscopy. Chest. 1977;72:105-7.

17. Baltch AL, Pressman HL, Hammer MC, Sutphen NC, Smith RP, Shayegani M. Bacteremia following dental extractions in patients with and without penicillin prophylaxis. Am J Med Sci. 1982;283:129-39. 
18. Minegishi S, Mochida Y, Furihata S, Ichikawa S, Fukuoka M, Kanbara K, Niinami H, Umemura S. A case of vertebral osteomyelitis and native valve endocarditis caused by Staphylococcus lugdunensis. I Jpn Soc Intensive Care Med. 2017:24:9-13.

19. Payne DN, Babb JR, Bradley CR. An evaluation of the suitability of the European suspension test to reflect in vitro activity of antiseptics clinically siginificant organisms. Left Appl Microbiol. 1999;28:7-12.

\section{Publisher's Note}

Springer Nature remains neutral with regard to jurisdictional claims in published maps and institutional affiliations.

Ready to submit your research? Choose BMC and benefit from:

- fast, convenient online submission

- thorough peer review by experienced researchers in your field

- rapid publication on acceptance

- support for research data, including large and complex data types

- gold Open Access which fosters wider collaboration and increased citations

- maximum visibility for your research: over $100 \mathrm{M}$ website views per year

At $\mathrm{BMC}$, research is always in progress.

Learn more biomedcentral.com/submissions 